\title{
ANTİK SPRADON TOPLUMU ÜZERİNE ANEMI ÇALIŞMASI
}

\section{Mustafa Tolga ÇIRAK*}

Atıf/O: Çırak, Mustafa Tolga (2018). Antik Spradon Toplumu Üzerine Anemi Çalışması, Hitit Üniversitesi Sosyal Bilimler Enstitüsü Dergisi, ANARSAN Sempozyumu Özel Sayısı, Ekim 2018, Cilt 11 Sayı 2, ss. 1203-1218

Özet: Antik çağlarda yaşamış toplulukların ve insanların maruz kalmış oldukları hastalıkları kemikler üzerinden inceleyen bir bilim dalı olan paleopatolojinin önemli ilgi alanlarından birisi de Anemi çalışmalarıdır. Anemi, kansızlık olarak isimlendirilir ve yeteri kadar demiri metabolizmasinda tutamayan veya barındıramayan insanlarda görülür. Anemi, özellikle beslenme ile ilgili çalışmalarda sıkça bakılan bir sağlık sorunudur. Antik dönem insanlarının kafataslarinda cribra orbitalia, porotic hyperostosis ve diploe kalinlaşması olarak ortaya çıkar. Bu çalışmaya konu olan Spradon Antik Kentine ait iskeletler, İstanbul İli Avcılar İlçe sinırlarındaki Ispartakule bölgesinde İstanbul Arkeoloji Müzeler müdürlüğü tarafindan 2011 senesinde ele geçmiştir. Bu bölgeden ele geçen 90 insan iskeleti üzerinde Cribra orbitalia, porotic hyperostosis ve diploe kalınlaşmasına hem cinsiyetlerde hem de yaş gruplarında bakılmıştır. Yapılan çalışmalar sonucunda toplumda yaklaşık \%12,2 civarında cribra orbitalia, \%13,3 iken diploe kalınlaşması \%8,8 olarak hesaplanmiştır. Cinsiyetler arası değerlendirmede kadınların cribra orbitalia oranı erkeklere göre daha fazladır. Erkeklerde ise porotic hyperostosis düzeyi kadınlardan fazladır. Diploe kalınlaşması ise yine bariz şekilde kadın bireylerde yüksek saptanmıştır. Cribra orbitaliaya bağlı olarak kadın bireylerde diploe kalınlaşmasından söz edilebilir. Spradon Toplumu çocuk bireylerinden sadece 2 bireyde porotic yapıyla karşılaşılması örnek sayısıyla bağlantılıdır. Spradon Geç Roma- Erken Bizans dönemi toplumunda beslenmeye bağlı sağlık sorunlarndan birisi olan anemi mevcuttur.

Anahtar Kelimeler: Spradon, Erken Bizans, Anemi, Cribra Orbitalia, Porotik Hyperostosis

Makale Geliş Tarihi:24.09.2018 / Makale Kabul Tarihi: 04. 10.2018

Bu makale Turnitin programinda kontrol edildi. This article was checked by Turnitin.

Bu makale ANARSAN sempozyumunda sunulmuş aynı başlıklı bildirinin tam metnidir.

* Dr. Öğr. Üyesi, Hitit Üniversitesi, Antropoloji Bölümü, mustafatolga@yahoo.com 


\section{Anemra Study On Ancient Spradon Population}

Citation/C: Çırak, Mustafa Tolga (2018). Anemia Study On Ancient Spradon Population Hitit University Journal of Social Sciences Institute, Symposium of AAHA, Special Issue, Year 11 Volume 2 October 2018, ss. 1203-1218

Abstract: Anemia is one of the important areas of interest in paleopathology, which is a branch of science that examines the diseases that people have been exposed to in ancient times through bones. Anemia is called anemia and is seen in people who cannot or cannot contain enough iron in their metabolism. Anemia is a health problem that is frequently researched, especially in nutritional studies. Cribra orbitalia, porotic hyperostosis and diploe occur in the skulls of ancient people. The skeletons of the ancient city of Spradon, which was the subject of this study, were discovered in 2011 by the Istanbul Archaeological Museums Directorate in the Ispartakule district in the Avcllar District of Istanbul. Cribra orbitalia, porotic hyperostosis and diploe thickening were examined in both sexes and age groups. As a result of the studies, approximately $12.2 \%$ cribra orbitalia in this population, $13.3 \%$ diploe was calculated as $8.8 \%$. Cribra orbitalia ratio is higher in females than in males. In males, porotic hyperostosis level is higher than females. Diploe was also significantly higher in female subjects. Due to Cribra orbitalia, diploe may be mentioned in female individuals. In the Spradon Population, only 2 individuals are related to the number of samples encountered in the porotic structure. Spradon In the late Roman-Early Byzantine period, anemia is one of the health problems related to nutrition.

Keywords: Spradon, Early Byzantium, Anemia, Cribra Orbitalia, Porotic Hyperostosis

\section{GİRIŞ}

Biyolojik bir canlı olan insanoğlu geçmişten günümüze kadar birçok farklı hastalık ve fiziki şartlarla mücadele etmek zorunda kalmıştır. Bu mücadele bazen insanoğlunun leyhine iken bazen aleyhine sonuçlanmıştır. Sosyo ekonomik şartlar insanların beslenmesinde önemli rol oynamaktadır. İnsanoğlu beslenmeyle ilgili olarak besin kaynaklarına ulaşımda bazen sorunlarla karşılaşabilmektedir. Besin kaynaklarına yeterince ulaşılamadığı dönemlerde ve bölgelerde beslenmeye bağlı sağlık sorunlarının ortaya çıkması 
kaçınılmaz bir sonuç olarak karşımıza çıkmaktadır. Dolayısıyla yeterli beslenemeyen insan gerek antik çağlarda gerek ise günümüzde birçok hastalıkla yüzleşmiştir ve yüzleşmeye devam etmektedir. Beslenmeye bağlı rahatsızlıklardan birisi de Anemidir. İnsanların her dönem maruz kaldığı Anemi, demir alımında yetersizlik olması durumunda gelişmektedir (Yurdakök ve İnce, 2009, 224). Sadece beslenmeye bağlı olmamakla birlikte yeteri kadar demiri beslenmeyle vücuduna alamayan insanda gelişme ihtimali çok fazladır. Kemikteki Demir düzeyi, aneminin göstergesi olduğu için birçok araştırmacı antik dönem insanlara ait kemikleri araştırmış ve demir eksikliğine bağlı gelişen aneminin varlığını tespit etmişlerdir (Aufderheide, 1989; Çırak, 2017, s. 177).

Demir, insanın hayat döngüsü içerisinde, hemoglobin aracılığıyla oksijenin ve elektronların taşınması görevini yerine getirmektedir. Demir mineralinin yetersizliğinde ciddi sağlık sorunlarının olması kaçınılmazdır (Aksoy, 2008). Beslenmenin yanında doğuştan de meydana gelen Anemi, hem antik dönemlerde hem de modern çağlarda insanın maruz kaldığı önemli bir hastalık olmuştur. Bebeklikten başlayarak yetersiz beslenmeye bağlı olarak gelişen Anemi kendisini kemik üzerinde farklı oluşumlarla göstermektedir. Antik dönemlere ait iskeletlerde demir eksikliğine bağlı anemi araştırması yapılırken kafatası önem taşımaktadır. Zira demir eksikliği anemisi kafatasında gözlenebilmektedir. Bu oluşumlar cribra orbitalia, porotic hyperostisis ve diploe kalınlaşması olarak ortaya çıkabilmektedir. Antropolojik çalışmalarda yoğun olarak Bazen sadece 1 belirti ile kendisini gösterirken bazen de bu 3 belirti de aynı bireyde görülebilmektedir. Cribra orbitalia ve porotic hyperostosis görünüş olarak benzemekle birlikte kafatasında meydana geldikleri bölgeye göre farklı isimle anılmaktadır. Zira cribra orbitalia gözün orbit tavanında oluşurken, porotic hyperostosis kafatasının özellikle diploe kısmında çokça görülebilmektedir (Walker ve ark. 2009).

Antropologlar, anemi araştırmaları yaparken sıklıkla cribra orbitalia ve porotic hyperostosis mevcudiyetini araştırırken (Sevim, 1998, s. 230-231) bu 2 oluşumun sonucunda oluşabilen diploe kalınlaşması da anemiye dair önemli ipuçları vermektedir.

\section{MATERYAL VE METOT}

Cribra orbitalia, porotic hyperostisis ve diploe kalınlaşması araştırması yapılan iskeletler İstanbul İli, Avcılar İlçesi, Ispartakule mevkiinde İstanbul Arkeoloji Müzeleri Müdürlüğü tarafından 2011 yılında yapılan kazı çalışmaları 
sırasında elde edilmiştir (Resim 1). İskeletler Geç Roma - Erken Bizans dönemine tarihlendirilmiştir. Spradon Toplumuna ait iskeletlerin yaş ve cinsiyet analizleri araştırmacı Şarbak ve arkadaşları tarafından yapılmıştır Şarbak, 2017, s.30).

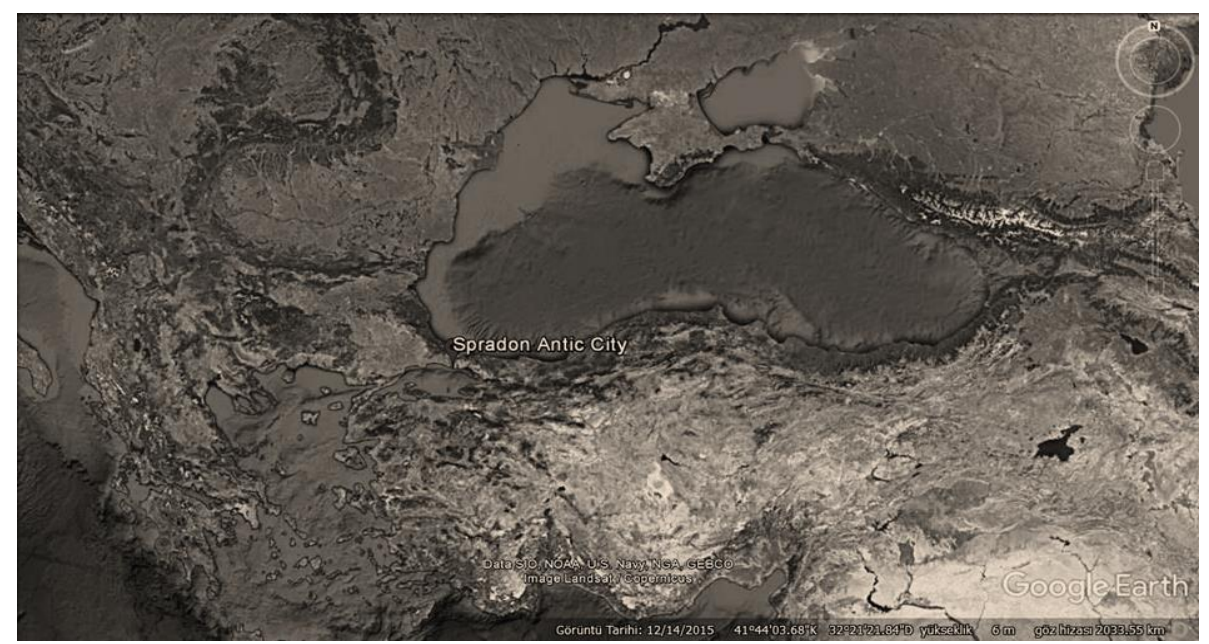

Resim 1 : Spradon Antik Kentinin Yeri

Spradon Toplumu fetüs, bebek, çocuk, adölesan ve yetişkin olarak toplam 90 bireyden oluşmaktadır. Toplumun cinsiyet dağılımına bakıldığında fetüs 1 $(\% 1,11)$, bebek $8(\% 8,88$, çocuk $7(\% 7,78)$, adölesan $2(\% 2,22)$, kadin 38 $(\% 42,22)$, erkek 31 (\%31). 3 bireyin ise cinsiyeti belirlenememiştir (Şarbak ve ark,2017) (Tablo 1).

Spradon Antik Kentine ait 90 bireyden 38'i kadın, 31’i erkek ve 7 çocuk birey olmak üzere toplam 76 bireyde cribra orbitalia, porotic hyperostosis ve diploe kalınlaşmasının var olup olmadığı araştırılmıştır. Mevcut kafatasları üzerindeki cribra orbitalia, diploe kalınlaşması ve porotic hyperostosis gözle ve büyüteçle tespit edilmeye çalışılmıştır.

Araştırmacı Şarbak ve arkadaşları Spradon Toplumunun yaş dağılımını da araştırmışlardır. Yaş grupları; Bebek (0-3 Yaş); Çocuk (3-12 yaş); Adölesan (12-20 yaş); Genç Yetişkin (20-35 yaş); Orta Yetişkin (35-50 yaş); İleri Yetişkin $(50+)$ yaş kategorisinde değerlendirilmiştir (White,2012). 1 birey Fetüs $(\% 1,11), 8$ birey bebek $(\% 8,88), 7$ birey çocuk $(\% 7,78), 2$ birey adölesan ( \% 2,22), 22 birey genç yetişkin $(\% 24,44), 32$ birey orta yetişkin $(\% 35,55), 8$ birey ileri yetişkin $(\% 8,88)$ 'dir. Bireylerden 7 'sinin $(\% 7,78)$ yetişkin oldukları 
saptanmış ancak yaşları tespit edilemediğinden bir yaş grubuna konulamamıştır (Şarbak ve ark., 2017, s. 29-30)

Kadın ve erkeklerin yaş dağılımlarına bakıldığında ise kadınlarda 38 bireyden 14 'ü genç yetişkin, 14'ü orta yetişkin, 6'sı ileri yetişkin ve 4'ü yaş grubu ayırt edilemeyen yetişkin bireylerdir. 31 erkek bireyin ise 8'i genç yetişkin, 18'i orta yetişkin, 2'si ileri yetişkin, 7'si yaş grubu belirlenemeyen yetişkin olarak belirlenmiştir.

Tablo 1: Spradon Toplumunda Cinsiyet Dağılımı Grafiği (Şarbak ve Ark., 2017, s. 30)

\begin{tabular}{|l|l|l|}
\hline \multicolumn{2}{|l|}{ Cinsiyet Dağılımı } & $\%$ \\
\hline Kadın & 38 & 42,22 \\
\hline Erkek & 31 & 34,44 \\
\hline Çocuk & 7 & 7,78 \\
\hline
\end{tabular}

\section{BULGULAR VE DEĞERLENDİRMELER}

Spradon Toplumu içerisinde kadınların sayısı 38'dir. Ve tüm toplum içerisinde kadın bireylerin oranı \%42,22'dir. Spradon toplumu kadın bireylerden 5 tanesinde Cribra orbitalia'ya rastlanmıștır. Bu sayı tüm kadınların \%13,2'sine denk gelmektedir. Toplumun geneline bakıldığında toplum içerisindeki cribra orbitaliaya sahip kadın bireyin oranı \%5,6'dır. Bu oran diğer cinsiyet grupları göz önüne alındığında en yüksek oranı vermektedir.

Spradon Toplumunda cribra orbitalia, porotic hyperostosis veya diploe kalınlaşmasına sahip bireyler göz önünde bulundurularak yapılan değerlendirmede toplumda toplam 11 bireyde cribra orbitalia tespit edilmiştir. Bunlardan 2 tanesi 10 yaşında M9 birey numaralı ve 14 yaşında M 36 birey numaralı 2 çocukta görülmektedir. Spradon toplumunda bulunan toplam 38 kadın bireyden 5 tanesinde cribra orbitalia tespit edilmiştir. Erkek bireylerde ise 4 bireyde cribra orbitalia saptanmıştır. Toplumun genel sayısı dikkate alınarak yapılan hesaplamada tüm toplum genelinde $\% 12,2$ 'lik cribra orbitalia oranı hesaplanmıştır. Toplum genelindeki porotic hyperostosisli birey sayısı ise 12'dir. Cribra orbitalia saptanan M 9 çocuk bireyinde porotic hyperostosis de mevcuttur (Resim 2) 


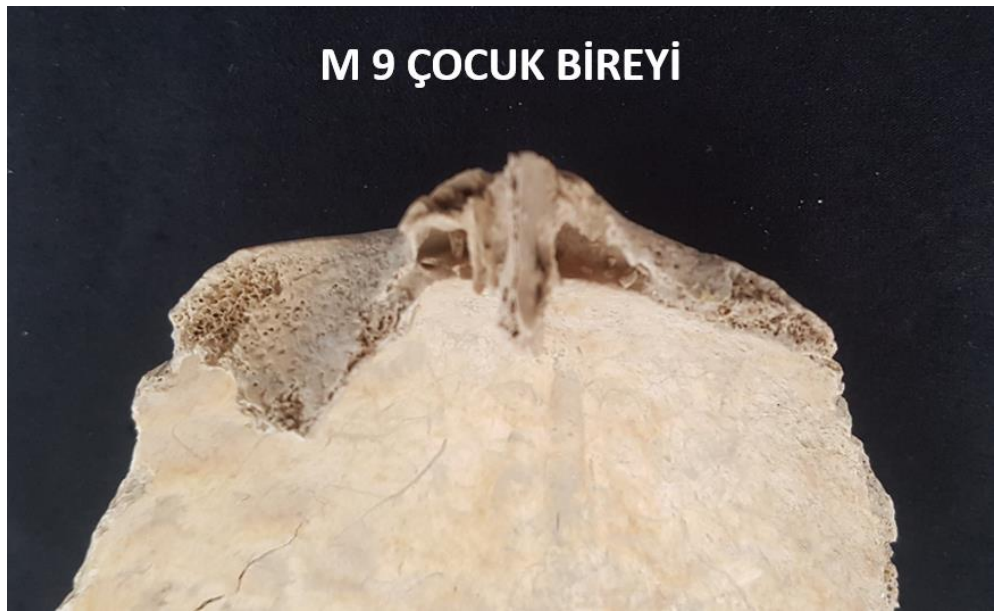

Resim 2: M9 Çocuk bireyinde cribra orbitalia

Porotic hyperostosisin toplum içinde görülme sıklı̆̆ ise \%13,3 olarak tespit edilmiştir. Spradon toplumunda ayrıca 8 bireyde diploe kalınlaşması saptanmıştır. Toplum içinde diploe kalınlaşmasının görülme sıklığı ise \% 8,9'dur. Kadin bireylerden M 23-4 bireyinde Cribra orbitalia, porotic hyperostosis ve diploe kalınlaşmasının her 3'ü de mevcuttur (Resim 3),(Tablo 2)

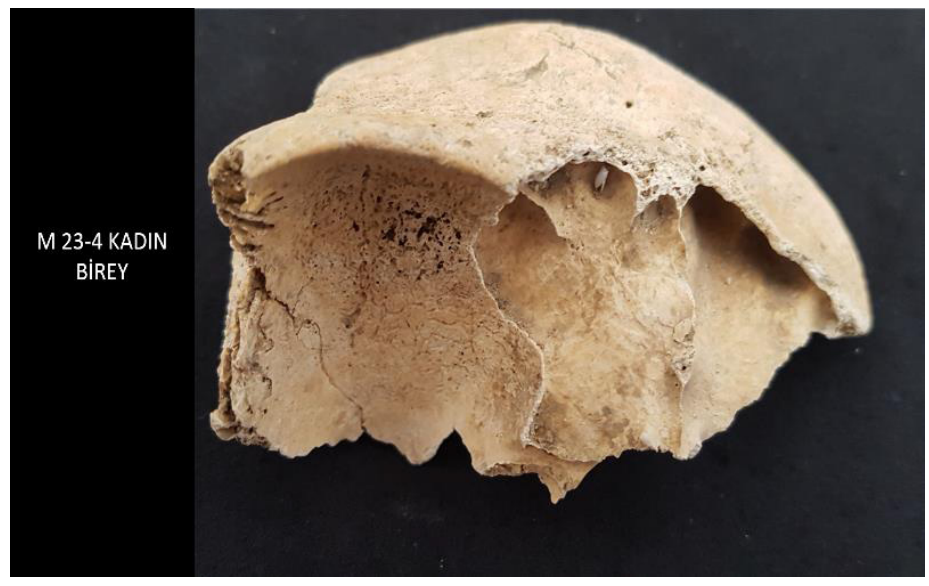

Resim 3: M 23-4 Kadin bireyde Cribra Orbitalia 
Tablo 2: Spradon Toplumu Bireylerinde C.O, P.H ve D.K

\begin{tabular}{|c|c|c|c|c|}
\hline $\begin{array}{l}\text { Birey } \\
\text { No }\end{array}$ & Cinsiyet & $\begin{array}{c}\text { Cribra } \\
\text { Orbitalia (C.O.) }\end{array}$ & $\begin{array}{c}\text { Porotic } \\
\text { Hyperostisis } \\
\text { (P.H.) }\end{array}$ & $\begin{array}{c}\text { Diploe } \\
\text { Kalınlaşması } \\
\text { (D.K.) }\end{array}$ \\
\hline$M 36$ & Çocuk & + & & \\
\hline$M 36-4$ & Erkek & + & & \\
\hline$M 44 / 3$ & Kadın & + & + & \\
\hline M III & Erkek & + & & \\
\hline M 9 & Çocuk & + & + & \\
\hline$M 25 / 4$ & Erkek & & + & \\
\hline$M$ 44-1 & Erkek & & + & \\
\hline M 35 & Kadın & & + & \\
\hline $35-4$ & Erkek & + & + & \\
\hline$M 23-4$ & Kadın & + & + & + \\
\hline$M 26-4$ & Kadın & + & & \\
\hline M 36-3 & Erkek & & + & \\
\hline$M$ 35-3 & Erkek & & + & + \\
\hline M 25-1 & Kadin & + & & \\
\hline$M$ 36-2 & Erkek & + & + & \\
\hline$M 46-2$ & Kadın & & + & \\
\hline M II & Kadın & & & + \\
\hline$M$ 35- 6 & Kadın & + & + & \\
\hline NO YOK & Kadın & & & + \\
\hline M 18 & Kadın & & & + \\
\hline M 54 & Kadin & & & + \\
\hline$M$ 54-2 & Kadın & & & + \\
\hline
\end{tabular}




\begin{tabular}{lllll}
\hline M 23-3 & Kadın & & & \\
& GENEL \% & 12,2 & 13,3 & 8,9 \\
\hline
\end{tabular}

Spradon Toplumu cinsiyet farklılıkları göz önüne alınarak değerlendirmeler yapılmıştır. Buna göre kadın bireylerde cribra orbitalia görülme sıklığ1 5 birey ile \%5,6'dır. Kadın bireylerin tüm toplumundaki sayısıyla cribra orbitaliaya sahip kadın bireyler oranlandığında \%13,2'lik bir cribra orbitalialı kadın birey oranıyla karşılaşılmaktadır. Spradon toplumu yetişkin bireyleri içerisinde kadın bireylerin ortalaması ise \% 7,2'dir. 23-4 genç yetişkin kadın birey, cribra orbitalia, porotic hyperostosis ve diploe kalınlaşmasının her 3 'üne de sahiptir.

Porotic hyperostosise sahip Spradon kadın birey sayısı da tıpk1 cribra orbitalia da olduğu gibi 5'tir. Dolayısıyla kendi cinsiyet grupları düşünüldüğünde toplum genelinde $\% 5,6$ lik bir porotic hyperostosis oranına sahip olduğu görülmektedir. Porotic hyperostosisli kadın oranı tüm kadınlar içerisinde \% 13,2 iken yetişkin Spradon toplumu arasında oran1 \%7,2'dir. Kadın bireylerde diploe kalınlaşması da mevcuttur. Spradon toplumu kadın bireylerin 7 tanesinde diploe kalınlaşması tespit edilmiştir. Toplum içerisindeki toplam 8 kafatasında görülen kalınlaşmanın 7 tanesi kadın bireylerde tespit edilmiştir. Toplumun genelinde bu oran \%7,8 iken yetişkin bireyler arasında \% 10,1'lik bir oran mevcuttur. Kadın bireyler arasında ise \%18,4'tür (Tablo 3). Yani yaklaşık her 5 kadın bireyden 1'inde diploe kalınlaşması mevcuttur (Resim 4)

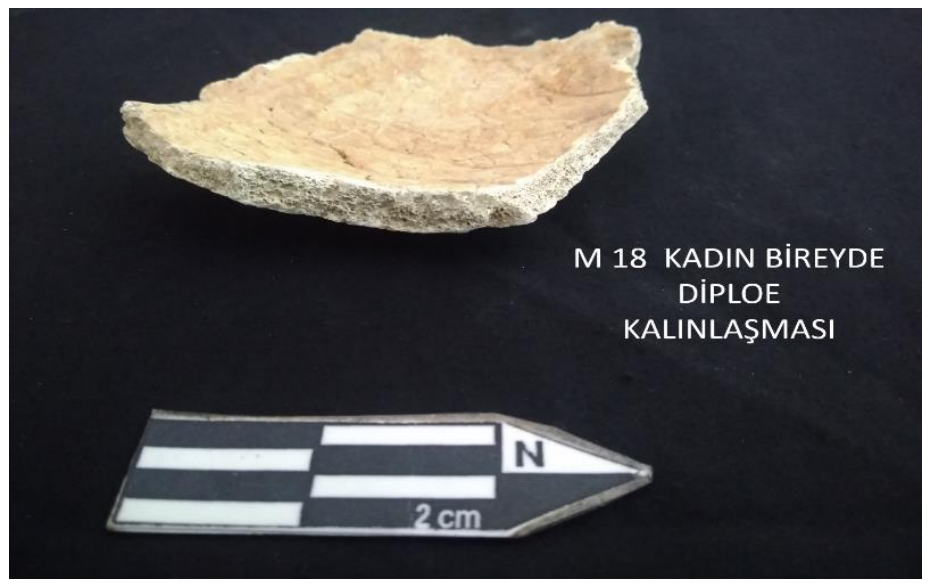

Resim 4: M 18 Kadın bireyde Diploe Kalınlaşması 
Tablo 3: Spradon Toplumu Kadın Bireylerinde C.O., P. H. Ve D. K.

\begin{tabular}{|c|c|c|c|}
\hline KADIN & $\begin{array}{c}\text { Cribra } \\
\text { Orbitalia (C.O) }\end{array}$ & $\begin{array}{c}\text { Porotic } \\
\text { Hyperostosis } \\
\text { (P.H.) }\end{array}$ & $\begin{array}{c}\text { Diploe } \\
\text { Kalınlaşması } \\
\text { (D.K.) }\end{array}$ \\
\hline 46-2 Genç Yet. & & + & \\
\hline m II Orta Yet. & & & + \\
\hline M35-6 Genç Yet. & + & + & \\
\hline NO YOK & & & + \\
\hline M 18 Orta Yet. & & & + \\
\hline M 54Genç Yet. & & & + \\
\hline 54-2 Orta Yet. & & & + \\
\hline 23-3 Genç Yet. & & & + \\
\hline 44/3 Genç Yet. & + & + & \\
\hline M35 Ileri Yet. & & + & \\
\hline 26-3 Genç Yet. & + & & \\
\hline 25-1 Orta Yet. & + & & \\
\hline 23-4 Genç Yet. & + & + & + \\
\hline CİNSİYET İÇİ & 13,2 & 13,2 & 18,4 \\
\hline ERİŞKİN & 7,2 & 7,2 & 10,1 \\
\hline GENEL & 5,6 & 5,6 & 7,8 \\
\hline
\end{tabular}

Spradon Toplumu erkek bireylerden 4 bireyde cribra orbitalia mevcuttur (Resim 5). Bunun toplum genelindeki oran1 \% 4,4'tür. Erkek bireylerin toplum içerisindeki sayıs1 31'dir. Cribra orbitalialı bireylerin erkek bireyler içindeki oranı ise \%12,9'dur. Bu oran kadınlardan daha düşük seviyededir. Yetişkin bireyler içerisindeki cribra orbitalialı erkek birey oranı \%5,7'dir. 


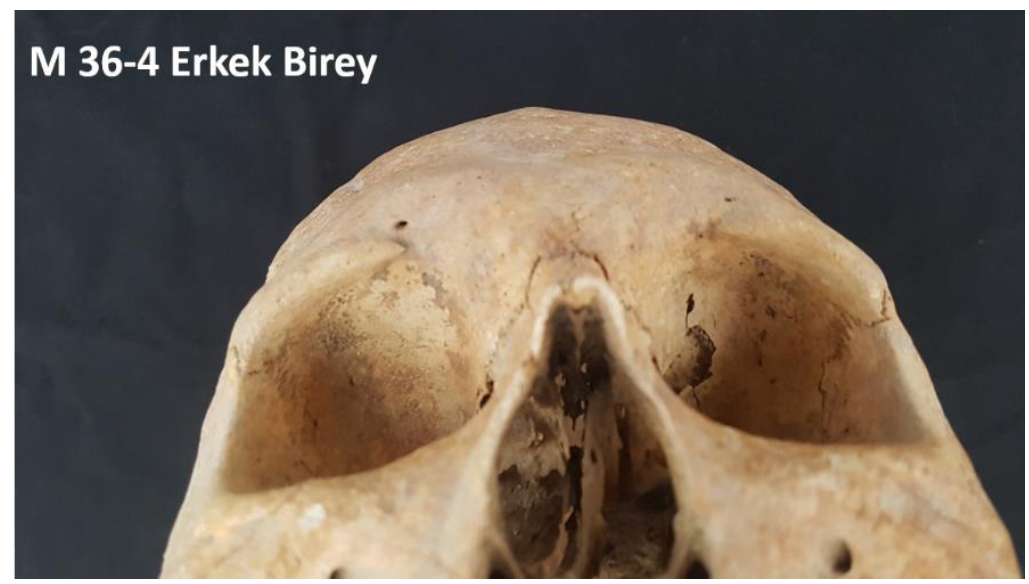

Resim 5: M 36-4 Erkek Bireyinde Cribra Orbitalia

Erkek bireylerdeki porotic hyperostosis sayısı cribra orbitaliaya göre fazladır. 6 erkek bireyde porotic yapı mevcuttur. Bunun erkek bireyler arasindaki oranı \%19,4'tür. Kadın bireylerde olduğu gibi yaklaşık her 5 erkek bireyden 1 'inde porotic yapı ile karşılaşılmaktadır (Resim 6). Yetişkin bireylerde ise porotic yapıl1 erkek bireylerin oranı \%8,7'dir.

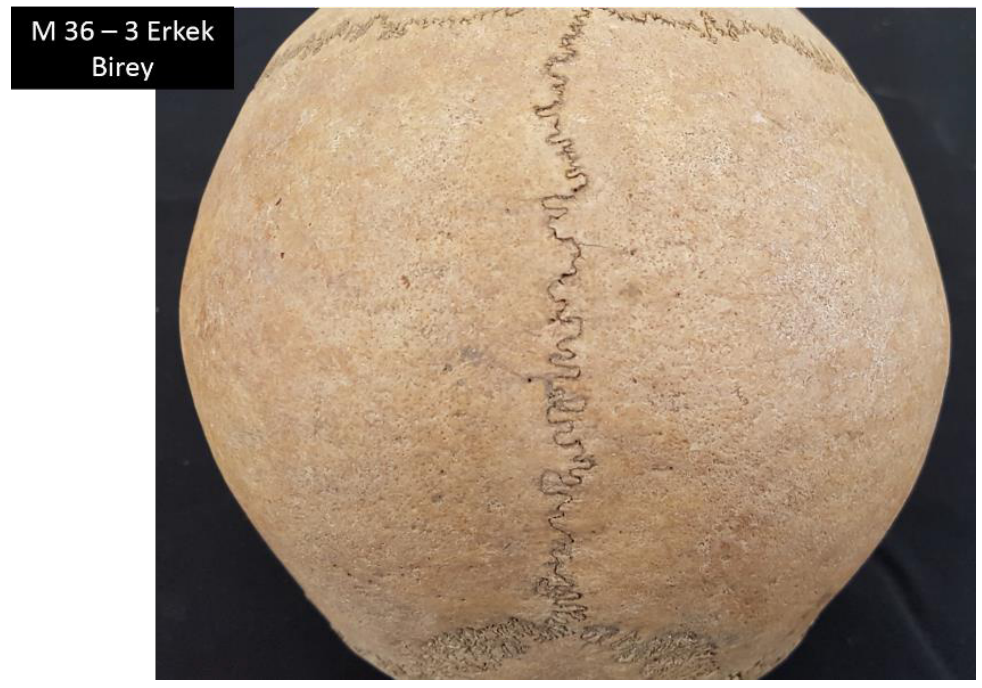

Resim 6: M 36 - 3 Erkek Bireyde Porotic Hyperostosis 
Erkek bireylerde kadınlara göre diploe kalınlaşması daha az seviyededir. Sadece 1 bireyde diploe kalınlaşması tespit edilmiştir. Orta Yetişkin M 33-4 erkek bireyde aynı zamanda porotic hyperostosis de mevcuttur (Resim 7,8).

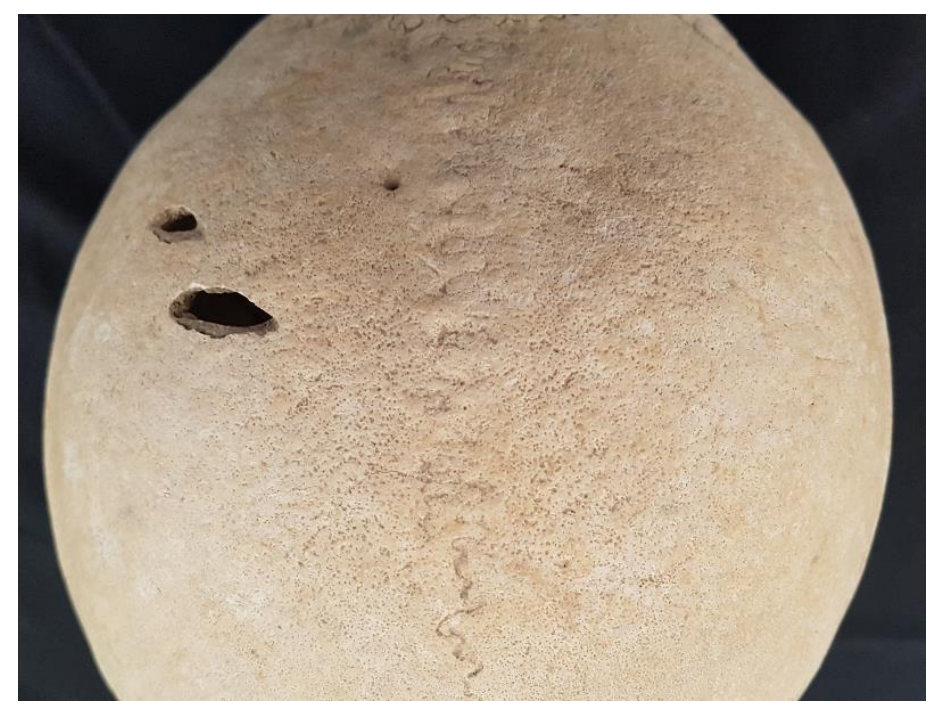

Resim 7: M 35 - 3 Erkek Bireyde Porotic Hyperostosis

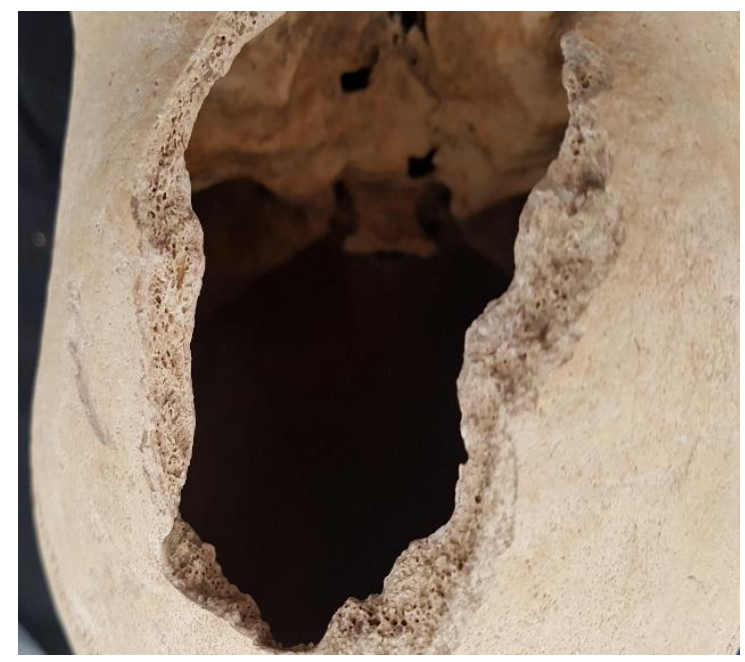

Resim 8: M 35 - 3 Erkek Bireyde Diploede Kalınlaşma 
Toplum geneline oranlandığında bu sayı \%1,1'e denk gelmektedir. Yetisskin bireyler arasında ise \%1,4'lük bir grubu temsil eden genç yetişkin erkek bireyler içerisinde yaklaşı $\% 3,2$ 'lik bir diploe kalınlaşması olduğu söylenebilir (Tablo 4).

Tablo 4: Spradon Toplumu Erkek Bireylerinde C.O., P. H. Ve D. K.

\begin{tabular}{|c|c|c|c|}
\hline ERKEK & $\begin{array}{c}\text { Cribra } \\
\text { Orbitalia (C.O) }\end{array}$ & $\begin{array}{c}\text { Porotic } \\
\text { Hyperostosis } \\
\text { (P.H.) }\end{array}$ & $\begin{array}{c}\text { Diploe } \\
\text { Kalınlaşmas1 } \\
\text { (D.K.) }\end{array}$ \\
\hline MIII Genç Yet. & + & & \\
\hline 25.4 Orta Yet. & & + & \\
\hline 44-1 Genç Yet. & & + & \\
\hline 35-4 Genç Yet. & + & + & \\
\hline 36-3 Genç Yet. & & + & \\
\hline 35-3 Orta Yet. & & + & + \\
\hline 36-2 Orta Yet. & + & + & \\
\hline 36-4 Yetişkin & + & & \\
\hline GRUP İÇİ & 12,9 & 19,4 & 3,2 \\
\hline ERİŞKİN & 5,7 & 8,7 & 1,4 \\
\hline GENEL & 4,4 & 6,7 & 1,1 \\
\hline
\end{tabular}

Spradon Toplumunda yaş dağılımları göze alınarak değerlendirme yapılmıştır. Spradon toplumunda yetişkinlerin toplam sayısı 69'dur. Yetişkinleri 22 birey genç yetişkin, 32 birey orta yetişkin, 8 birey ileri yetişkin ve 7 birey grubu belirlenemeyen yetişkin bireyler temsil etmektedir (Şarbak ve ark.2017, s. 30).

Genç yetişkin bireylerden toplam 6 bireyde cribra orbitalia mevcuttur. Bu say1 tüm yaş grupları içerisindeki en fazla cribra orbitalia sayısıdır. Toplumun genelinde orta yetişkin sayısı genç yetişkinlere göre daha fazla olmasına rağmen cribra orbitalia sayısı orta yetişkinlerden daha fazla genç yetişkinlerde gözükmesi ilginçtir. Toplam 4 bireyde hem cribra orbitalia hem de porotic yapı mevcut iken genç yetişkin kadın birey olan M 23-4 bireyinde cribra 
orbitalia, porotic hyperostosis ve diploe kalınlaşmasının her 3'ü de mevcuttur. Porotic hyperostosis cribra orbitaliaya göre 1 genç yetişkin birey daha fazladır. Tıpkı cribra orbitalia da olduğu gibi yaş grupları içerisinde en yoğun porotic yapı genç erişkilerde mevcuttur (Tablo 5).

Tablo 5: Spradon Toplumu Genç Yetişkinlerde C.O., P. H. Ve D. K Dağılımı

\begin{tabular}{|c|c|c|c|}
\hline $\begin{array}{l}\text { GENÇ } \\
\text { ERIŞKİN }\end{array}$ & $\begin{array}{l}\text { Cribra } \\
\text { Orbitalia (C.O) }\end{array}$ & $\begin{array}{l}\text { Porotic } \\
\text { Hyperostosis } \\
\text { (P.H.) }\end{array}$ & $\begin{array}{l}\text { Diploe } \\
\text { Kalınlaşması } \\
\text { (D.K.) }\end{array}$ \\
\hline M III & + & & \\
\hline$M$ 44-1 & & + & \\
\hline M 35-4 & + & + & \\
\hline M 36-3 & & + & \\
\hline$M$ 46-2 & & + & \\
\hline$M$ 35- 6 & + & + & \\
\hline$M 54$ & & & + \\
\hline $23-3$ & & & + \\
\hline $44 / 3$ & + & + & \\
\hline $26-3$ & + & & \\
\hline $23-4$ & + & + & + \\
\hline
\end{tabular}

Spradon Toplumunda orta yetişkin birey sayıs1, 32 birey ile toplumun en fazla yetişkin grubunu temsil etmektedir (Şarbak ve ark.2017, s. 30). Yaş grupları içerisinde en fazla sayıyı temsil eden orta yetişkin bireylerinde gerek cribra orbitalia, gerek porotic yapı genç yetişkine göre daha azdır. Sadece diploe kalınlaşmasında genç yetişkine göre sayıca fazladır. Orta yetişkin Spradon toplumunda 2 bireyde cribra mevcuttur. Porotic yap1 ise orta yetisskin yass grubunda 3 bireyde mevcuttur. M 36-2 bireyinde hem cribra orbitalia hem de porotic hyperostosis mevcuttur. Diploe kalınlassması ise 4 bireyde tespit edilmiştir. M 35-3 bireyinde hem diploe kalınlaşması hem de porotic yap1 mevcuttur (Tablo 6). 
Tablo 6: Spradon Toplumu Orta Yetişkinlerinde C.O., P. H. Ve D. K Dağılımı

\begin{tabular}{|c|c|c|c|}
\hline $\begin{array}{l}\text { ORTA } \\
\text { ERİŞKİN }\end{array}$ & $\begin{array}{l}\text { Cribra Orbitalia } \\
\text { (C.O) }\end{array}$ & $\begin{array}{l}\text { Porotic Hyperostosis } \\
\text { (P.H.) }\end{array}$ & $\begin{array}{l}\text { Diploe Kalınlaşması } \\
\text { (D.K.) }\end{array}$ \\
\hline M 25.4 & & + & \\
\hline M 35-3 & & + & + \\
\hline M 36-2 & + & + & \\
\hline M II & & & + \\
\hline M 18 & & & + \\
\hline M 54-2 & & & + \\
\hline M 25-1 & + & & \\
\hline
\end{tabular}

Spradon Toplumunda ileri yetişkin birey sayıs1 8'dir. Bu ileri yetişkin bireyler içerisinde sadece M 35 bireyinde porotic hyperostosis tespit edilmiştir. Diğer bireylerde herhangi bir anemi belirtisine rastlanmamıştır. Bunda en büyük etken, yeteri sayıda yetisskin birey olmaması gösterilebilir (Tablo 7).

Tablo 7: Spradon Toplumu İleri Yetişkinlerinde C.O., P. H. Ve D. K Dağılımı

\begin{tabular}{l|ccc} 
& Cribra & Porotic & Diploe \\
İLERI & Orbitalia & Hyperostosis & Kalınlaşmast \\
ERIŞKİ & (C.O) & (P.H.) & (D.K.) \\
\hline M 35 & & + &
\end{tabular}

\section{TARTIŞMA VE SONUÇ}

Anemi, geçmişten günümüze kadar gelen süreçte gerek beslenmeye bağl1 olarak gerek ise kalıtımsal yollarla insanların maruz kaldığı önemli bir sağlık 
sorunudur. Ve özellikle beslenmeye bağlı aneminin insan vücudunda bir takım belirtileri mevcuttur. Cribra orbitalia ve porotic hyperostosis bu belirtilerden en önemlileridir. Aneminin tek bir nedeninin olmaması yanında özellikle yetersiz beslenmenin aneminin oluşmasında önemli etken olduğu söylenebilir (Ortner ve ark., 1999, s. 321). 1950'lerden beri, kronik demir eksikliği anemisi her iki durumun muhtemel nedeni olarak geniş çapta kabul görmüştür (Walker, 2009,s.109). Cribra orbitaliaya bağlı olarak diploede kalınlaşmanın meydana geldiği de düşünülmektedir. Buna bağlı olarak cribra orbitalialı bireyler üzerinde radyografik incelemeler yapılmış ve ilişkileri ortaya konmaya çalışılmıştır (Yılmaz ve ark., 2014, Naaved ve ark.,2012, s. 394) Ancak bunun cribra orbitaliadan bağımsız olabileceğini de düşünen bilim adamları mevcuttur. Cribra orbialiaya sahip olunduğu halde diploede kalınlaşma olmayabileceği ile ilgili çalışmalar yapılmıştır (Rivera ve Mirazon, 2017, s.96-96). Spradon toplumu üzerinde yapılan çalışmalarda da bu duruma benzer sonuçlar elde edilmiştir. Sadece erkek bireylerden 1 bireyde diploe kalınlaşması gözükmesi, buna karşın kadın bireylerde daha fazla diploe kalınlaşması ile karşılaşılması bu çalışma ile paralellik gösterir. Cribra orbitalia ve porotic hyperostosisin tek nedeninin anemi olmadığ bilinmektedir. Spradon toplumunda hem kadın hem erkek hem de çocuk bireylerde cribra orbitalia ve porotic yapıya rastlanması bu olgunun daha çok beslenme ile ilgili olduğunu göstermektedir. Ayrıca özellikle kadın bireylerden genç erişkin kadınlarda cribra orbitalia ve porotic hyperostosisin çok yoğun gözlemlenmesi toplum içerisinde beslenme kaynaklı bir farklılaşma olabileceğini düşündürmektedir. Sosyo - ekonomik anlamda erkeklerin statüsü toplum içerisinde daha yüksektir. Bunun karşlığında da besin öğelerine kadın bireylere göre daha rahat ulaşma imkanına sahip olunabilmektedir. Dolayısıyla Spradon Toplumunda sosyal statü kaynaklı bir beslenme farklılı̆g olabileceği, bunun sonucu olarak da kadın ve erkek bireyler arasında aneminin farklı seyredebileceği hipotezi öne sürülebilir. Ayrıca az sayıda da olsa ileri yetişkin bireylerde sadece 1 bireyde porotic hyperostosisin olması toplum içinde besinleri elde etme konusunda genç bireylere oranla daha şanslı olunabileceğini göstermektedir.

\section{TEŞEKKÜR}

Spradon Toplumu iskeletlerinin çalışılmasına olanak veren İstanbul Arkeoloji Müzeleri Müdürü Sayın Zeynep Kızıltan'a, Müdür yardımcısı Tuğçe Akbaytogan'a müze çalışanlarına ve Hitit Üniversitesi Antropoloji Bölümü öğrencilerine teşekkür ederim. 


\section{KAYNAKÇA}

Aksoy, M., (2008). Beslenme Biyokimyas1, Hatipoğlu Yayınevi, Ankara.

Aufderheide, A. C., (1989). "Chemical Analysis of Skeletal Remains", Reconstruction of Life from the Skeleton, 237-260, Willey Liss., Florida.

Çırak, M.T., (2017), Anemi Görülen Bireylerdeki Element Seviyelerinin Antropolojik Açıdan Değerlendirilmesi, Turkish Studies, Volume 12/29, p. 169-178.

Naveed, H., Abed, S.F, Davagnanam, I., Uddin, JM, Adds P.J. (2012), Lessons From The Past: Cribra Orbitalia, An Orbital Roof Pathology, Orbit. Dec;31(6):394-409.

Ortner, D.J., Kimmerle, E. and Diez, M. (1999), Probable Evidence of Scurvy in NonAdults from Archaeological Sites in Peru. American Journal Physical Anthropology, 108:321-331.

Rivera, F. ve Mirazon, L.M.,(2017), New Evidence Suggesting A Dissociated Etiology For Cribra Orbitalia And Porotic Hyperostosis. Am. J. Phys. Anthropol. Sep;164(1):76-96.

Sevim, A., (1998). "Eski Anadolu Toplumlarında Gözlenen Bir Paleopatolojik Doku Bozukluğu: Porotic Hyperostosis”, Antropoloji, 13: 229-244.

Şarbak, A., Çırak, M.T., Çırak, A., (2017), Osteoarchaeological Investigations of Metopic Suture in The Late Roman Period in Spradon, Mediterranean Archaeology and Archaeometry, Vol. 17, No 3, pp. 27-38.

Walker P.L., Bathurst R.R., Richman R., Gjerdrum T., and Andrushko V.A., (2009), The Causes Of Porotic Hyperostosis And Cribra Orbitalia: A Reappraisal Of The İronDeficiency-Anemia Hypothesis. American Journal of Physical Anthropology, 139: 109-125.

Yılmaz, H., Pehlevan,C., Göksal, N., (2014), Çatak (Van) İskeletlerinin Paleopatolojik Analizi, International Journal of Human Science, 11(2), s:1327-1350.

Yurdakök, K., İnce, O. T., (2009). "Çocuklarda Demir Eksikliği Anemisini Önleme Yaklaşımları", Çocuk Sağlığı ve Hastalıkları Dergisi, 52: 224- 231. 